\section{Check for updates}

\section{AUTHOR:}

Anuschka Curran 1

Sandra Barn

AFFILIATION:

Unit for Environmental Sciences and Management, North-West University, Potchefstroom, South Africa

\section{CORRESPONDENCE TO:}

Sandra Barnard

EMAIL:

sandra.barnard@nwu.ac.za

DATES:

Received: 22 May 2020

Revised: 23 Nov. 2020

Accepted: 12 Feb. 2021

Published: 29 July 2021

\section{HOW TO CITE:}

Curran A, Barnard S. What is the role of zooxanthellae during coral bleaching? Review of zooxanthellae and their response to environmenta stress. S Afr J Sci. 2021;117(7/8), Art. \#8369. https://doi. org/10.17159/sajs.2021/8369

\section{ARTICLE INCLUDES: \\ 囚 Peer review}

$\square$ Supplementary material

DATA AVAILABILITY:

$\square$ Open data set

$\square$ All data included

$\square$ On request from author(s)

$\square$ Not available

凶 Not applicable

EDITORS:

Bettine van Vuuren iD

Sydney Moyo iD

\section{KEYWORDS:}

climate change, Symbiodinium, antioxidant enzymes, heat-shock proteins

\section{FUNDING:}

None

\title{
What is the role of zooxanthellae during coral bleaching? Review of zooxanthellae and their response to environmental stress
}

\begin{abstract}
Coral reefs are diverse and productive but sensitive ecosystems. Due to the impact of climate change, these organisms are in danger of dying out, mainly through the process of coral bleaching, which is the process by which zooxanthellae (algal endosymbionts) are expelled from their respective coral hosts, causing the coral to lose colour and become white. Coral bleaching has been linked to increases in sea surface temperatures as well as an increase in light intensity. We reviewed the different zooxanthellae taxa and their ecological traits, as well as the information available on the protective mechanisms present in zooxanthellae cells when they experience environmental stress conditions, such as temperature fluctuations, specifically concentrating on heat shock proteins and their response to antioxidant stress. The eight clades $(\mathrm{A}-\mathrm{H})$ previously recognised were reorganised into seven existing genera. Different zooxanthellae taxa exhibit different ecological traits such as their photosynthetic stress responses to light and temperature. Zooxanthellae have the ability to regulate the number and type of heat shock proteins (Hsps) they produce during a heat response. They can also regulate the host's respective Hsps. Antioxidant responses that can prevent coral hosts from expelling the zooxanthellae, can be found both within exposed coral tissue and the zooxanthellae cells. Despite the lower likelihood of bleaching in South African coral reefs, genetic engineering presents a useful tool to understand and adapt traits within zooxanthellae genotypes to help mitigate coral bleaching in the future.
\end{abstract}

\section{Significance:}

- Coral bleaching is the expulsion of zooxanthellae (algal symbionts) from the respective coral host, mainly due to elevated sea surface temperatures and light intensities, but numerous other factors, such as changes concerning salinity (ocean acidification), may also cause coral bleaching, although to a much lesser extent.

- A specific clade of zooxanthellae can be linked to their coral host's susceptibility to variation in oceanic temperatures, most probably by regulating both the host's respective heat shock proteins as well as their own.

- South African reefs have not experienced coral bleaching to the same degree as elsewhere in the world, mainly due to their unique reef topography and oceanic currents.

- Genetic bioengineering of zooxanthellae cells provides a plausible solution to save southern African coral reefs before it is too late.

\section{Introduction}

Coral reefs are one of the most diverse, productive and complex ecosystems on the planet, but due to global climate change, these phenomenal infrastructures are dying off, primarily through coral bleaching. ${ }^{1}$ Coral bleaching is now five times more common than it was 40 years ago, and the global proportion of corals affected by bleaching per year has risen from $8 \%$ in the 1980 s to $31 \%$ in $2016 .^{2}$ The western Indian Ocean has experienced bleaching events, which have been observed from 1983 up to 2016, with the most extreme event occurring during 1998. The bleaching events of 1998 and 2016 occurred as a result of abnormally high summer temperatures appearing concurrently with the El Niño Southern Oscillation. Numerous studies have been conducted on South African coral reefs since the 1998 El Niño, which had a devastating mass bleaching impact on other renowned coral reefs. ${ }^{3}$ In 2005, a warm-water anomaly that affected much of the southern Indian Ocean resulted in moderately high coral bleaching on Madagascan, Mozambican and South African reefs. ${ }^{4}$

Coral bleaching can be described as the process by which zooxanthellae (algal symbionts) are expelled from the gastrodermal cavity (tissue) of the respective coral host. Thereafter coral whitening occurs, displaying the $\mathrm{CaCO}_{3}$ skeletal structure of the coral which causes stress to the coral and it can then die. Most coral bleaching events are due to an increase in temperature above the normal stable temperature in which the holobiont survives. Scleractinian corals are reef-building corals that live in a mutualistic symbiotic relationship with single-celled zooxanthellae, referred to as dinoflagellates, belonging to the genus Symbiodinium. ${ }^{5}$ The specific clade to which these resident Symbiodinium cells belong, can be linked to their host's susceptibility to variation in oceanic temperatures, thus variation in thermal tolerance is observed among individual colonies and host species. ${ }^{6}$ In their study, LaJeneusse and co-workers ${ }^{6}$ used molecular, morphological, physiological, and ecological information and proposed that these clades that were previously identified are equivalent to different genera in the family Symbiodiniaceae.

Expulsion of zooxanthellae from the coral's internal tissues during coral bleaching is regulated by the rate of photoinhibition and photo-damage to the zooxanthellae's thylakoid membranes' integrity and fluidity. ${ }^{7}$ These regulating factors are also influenced by the respective zooxanthellae clade/genus as well as the scleractinian coral host. Both 
corals and zooxanthellae have many protective mechanisms against elevated temperatures and thermal stress, one of which is the induction of heat shock proteins (Hsps). According to Rosic and co-workers ${ }^{8}$, numerous Hsps exist and are responsible for different stress response behaviours in the holobiont.

Coral bleaching is directly linked to elevated sea surface temperatures (SSTs) as well as an increase in light intensity. Downs et al. ${ }^{9}$ suggested that elevated SSTs may result in an increased amount of reactive oxygen species (ROS) produced by the symbiont, which concurrently results in oxidative stress in both coral host and symbiont. During oxidative stress, ROS are produced in the endosymbiont's chloroplast, further producing hydrogen peroxide $\left(\mathrm{H}_{2} \mathrm{O}_{2}\right)$. $\mathrm{H}_{2} \mathrm{O}_{2}$ can thereafter diffuse into the coral's cytoplasm and cause oxidative damage to the coral tissue. Damage is not only caused in the host's tissue but also within the thylakoid membranes of the endosymbiont. ${ }^{10}$ Antioxidant response mechanisms are in place to prevent damage from increased levels of ROS such as antioxidant enzymes pathways including SOD (superoxide dismutase), ascorbate peroxidase and CAT (catalyse), which act together to inactivate superoxide radicals, neutralise hydrogen peroxide or inactive converted hydroxyl radicals $(\mathrm{OH})$ and prevent coral hosts from expelling their vulnerable endosymbionts. ${ }^{11}$

Genetic editing has become a useful tool in understanding and manipulating variables and systems within the biological world. Several studies have suggested that environmental bioengineering can be an important consideration for future coral reef restoration strategies. ${ }^{12,13}$ According to Levin et al. ${ }^{12}$, zooxanthellae have the potential to be genetically edited, but genetic editing poses genomic challenges which should first be understood.

Our aim was firstly to review the different zooxanthellae genotypes and their traits concerning environmental stress. Secondly, we reviewed the information available on the protective mechanisms present in zooxanthellae cells when they experience temperature fluctuations, specifically concentrating on heat shock proteins and the antioxidant stress response within the coral and their zooxanthellae endosymbionts. Thirdly, we investigated the possibility of applying genetic modification to enhance the stress tolerance of zooxanthellae species.

\section{Zooxanthellae genotypes}

Within the taxonomic group (genus) Symbiodinium, different Symbiodinium genotypes (Symbiodinium cells with somewhat different genetic make-ups) exhibit different traits, such as their photosynthetic stress responses to light and temperature. Therefore, genetic factors that contribute to differences in stress tolerance between these Symbiodinium genotypes can also influence the coral's gene expression and its bleaching susceptibility. ${ }^{12}$ It is therefore very important to understand these different genotypes better. Based on their genetic and physiological diversity, the Symbiodinium genotypes were firstly divided into eight clades (different groups of zooxanthellae that all evolved from a common ancestor) and classified from $\mathrm{A}$ to $\mathrm{H}$, whereby only six of these clades are in a mutualistic relationship with corals. ${ }^{14}$
Recently, however, the organisms within these alphabetic clades were reviewed by LaJeunesse et al. ${ }^{6}$ based on their genetic (phylogenetic), physiological, morphological, and ecological information. They further reorganised the zooxanthellae into seven existing genera within the family Symbiodiniaceae (a group of genera sharing a common attribute). This provided a more organised and systematic framework (Table 1). More genera may still be defined by other researchers. Therefore, for the rest of the review, the former clade designations will still be used.

Scleractinian corals (reef-building corals) increase their likelihood to resist thermal change by displacing their endosymbiont partners during temperature changes from a more thermal-sensitive zooxanthellae genotype to less thermal-sensitive zooxanthellae genotypes. This displacement of endosymbionts by the coral host is termed symbiont shuffling. ${ }^{15}$ Recent studies have shown that within most corals, clade C2 zooxanthellae (thermally sensitive) are displaced by clade D zooxanthellae (thermally tolerant) when subjected to elevated SSTs. The genus Cladocopium (corresponding to Clade $\mathrm{C}$ ) as redefined by LaJeneusse et al. ${ }^{6}$ is noted to be adapted to a wide range of temperatures and light intensities. According to Jones et al. ${ }^{15}$, type C2 Symbiodinium is known to be thermally sensitive, and only actively photosynthesises at $27^{\circ} \mathrm{C}$; type $\mathrm{C} 1, \mathrm{C} 13$ and $\mathrm{C} 15$ are not able to function optimally above $33^{\circ} \mathrm{C}$. Therefore, even within a single clade, different types and strains exhibit different temperature tolerances.

To date, the zooxanthellae from clade $D$ have been found to have exceptional thermal tolerance, thereby being a more thermally dominant clade. ${ }^{15}$ Corals containing clade D zooxanthellae generally inhabit warmer tropical waters, and therefore require more protection against elevated SSTs. Furthermore, members of the newly proposed genus Durusdinium (corresponding to clade D), as defined by LaJeneusse et al. ${ }^{6}$, are therefore also noted to be extremophiles, adapted to living in regions with large temperature variations. Clade $\mathrm{D}$ is often described as 'greedy' during a stress response, as these zooxanthellae retain a greater amount of their photosynthetically fixed carbon to mediate metabolic reactions within their cell structures against thermal fluctuations, thereby indirectly starving the host. ${ }^{15}$

Clade B zooxanthellae are normally found in cold-water corals and can tolerate a decrease in SSTs. ${ }^{14}$ Clades $A$ and $F$ are not as commonly found within the coral species as are clades $B, C$ and $D$, which might indicate that these types are more sensitive to thermal fluctuations or are specific to certain, not yet well-studied coral species. ${ }^{14}$ The genus Symbiodinium (that corresponds to clade A) is most adapted to living in high light intensities or variable light conditions. ${ }^{6}$

\section{Zooxanthellae and bleaching}

According to both Downs et al. ${ }^{9}$ and Carilli et al..$^{16}$, numerous protective and preventive mechanisms are in place within the zooxanthellae to decrease the effect of bleaching. These mechanisms include xanthophyll cycling, production of small heat shock proteins (sHsps), conformational change in lipid composition and the production of stress-stable enzyme complexes within the electron transport pathway (Figure 1).

Table 1: Recently redefined taxonomic designations of the well-known zooxanthellae clades into seven genera and their respective type species ${ }^{6}$

\begin{tabular}{l|l|l}
\hline \multicolumn{1}{c|}{ Former cladal designation } & \multicolumn{1}{c}{ Redefined genus } & \multicolumn{1}{c}{ Respective type species } \\
\hline Clade A (mostly free living) & Symbiodinium sensu stricto & S. natans \\
\hline Clade B (mostly found in cold-water corals) & Breviolum & B. minutum \\
\hline Clade C (mostly symbiotic and thermally sensitive) & Cladocopium & C. goreaui \\
\hline Clade D (mostly symbiotic and thermally tolerant) & Durusdinium & D. trenchii \\
\hline Clade E & Effrenium & E. voratum \\
\hline Clade F (mostly free living) & Fugacium & F. kawagutii \\
\hline Clade G & Gerakladium & G. endoclionum
\end{tabular}


Thermal tolerant cladal response upon heat stress

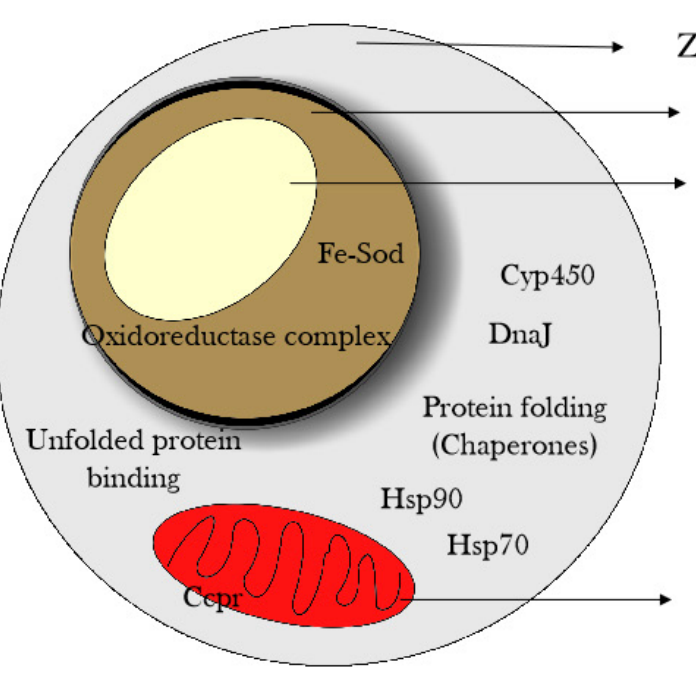

Thermal sensitive cladal response upon heat stress

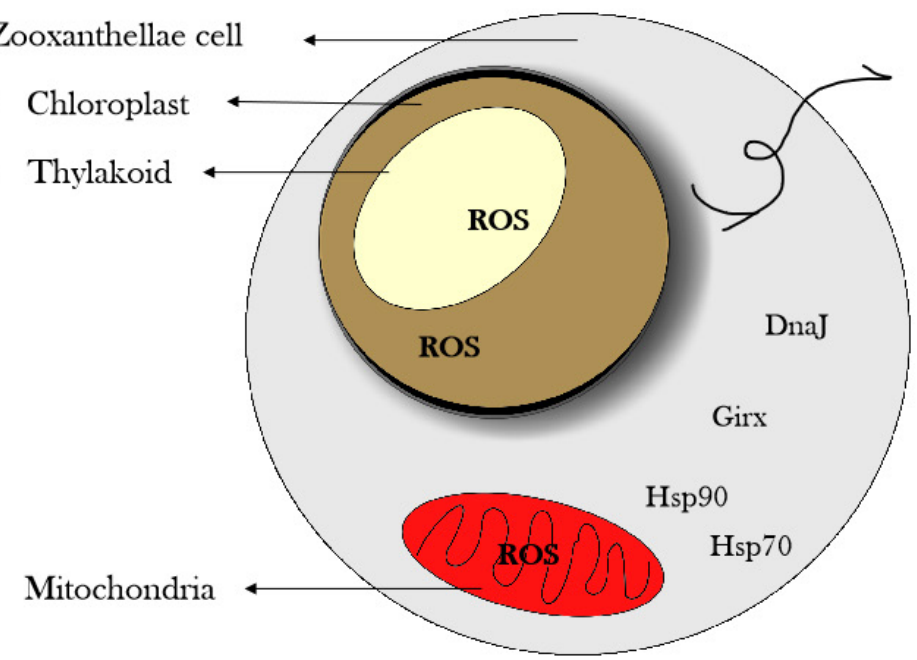

Figure 1: Protective mechanisms that are induced to actively counteract heat/thermal stress within both sensitive and tolerant zooxanthellae species according to Levin et al. ${ }^{17}$

Activated protective measures taken against induced thermal stress in thermal tolerant and thermal sensitive zooxanthellae endosymbionts, may be observed in Figure 1, as was discussed by Levin et al. ${ }^{17}$ Within a thermal tolerant zooxanthellae clade, both Hsp70 and Hsp90, as well as protein folding and unfolding chaperones such as DnaJ, and antioxidant enzymes such as Fe-SOD, are expressed and activated within the zooxanthellae cell, each within its respective organelles (chloroplast and mitochondria). With this rapid response, the zooxanthellae cells mediate thermal stress and can ensure protection against oxidative stress within their cellular compartments. Within a thermal sensitive zooxanthellae clade, these mediating responses are not as effectively activated. Thus, some Hsps are expressed and activated, but ultimately the cell still produces ROS that can cause damage to the thylakoid membrane within the chloroplast, and subsequently damage within other compartments of the cell.

Numerous factors such as salinity, pollution, temperature, and $\mathrm{pH}$, which are governed by $\mathrm{CO}_{2}$ emissions, fisheries, and tourism, may have an impact on the distribution and biodiversity of zooxanthellae and their respective coral hosts. Unfortunately, these environmental factors may also contribute to coral degradation and ultimately coral bleaching events, and may result in both coral and zooxanthellae community structure and diversity changes. According to Chauka et al. ${ }^{18}$, zooxanthellae diversity differs on account of many environmental aspects such as available light concentrations and light intensity tolerances, which may influence zooxanthellae distribution along environmental gradients due to photoprotection, acclimation, and their photosynthetic rates. In combination with symbiont shuffling, these changes are important cornerstones to understanding the adaptive capacity and nature of the entire coral holobiont and reef. Furthermore, Chauka et al. ${ }^{18}$ further state that during their sampling, different symbiont types (clades) within colonies in the same localities were also observed and obtained, which suggests intracolonic variation amongst the zooxanthellae.

\section{Photosynthetic dysfunction}

The general consensus is that mass coral bleaching is due to the dysfunction of photosynthetic processes (such as a pronounced reduction in the activity of photosystem (PS) II and linear electron transport) in the algal endosymbiont as a result of the combined action of elevated temperature and light stress.
Takahashi et al. ${ }^{7}$ and Smith et al. ${ }^{19}$ described thermal bleaching as photoinhibition of photosynthetic electron transport, such as the oxidation of plastoquinone by cytochrome complexes, reducing the excitation energy, and thereby suppressing the Calvin cycle and decreasing the rate at which photons are delivered to PSII within the zooxanthellae chloroplasts. Photodamage is due to the production of ROS in the thylakoid photosynthetic apparatus of the zooxanthellae, leading to oxidative stress within the holobiont (Figure 2).

Figure 2 demonstrates the process of oxidative coral bleaching and thermal stress response within both the zooxanthellae endosymbiont as well as its coral host. ROS are produced within the chloroplast of the zooxanthellae via several mechanisms associated with photosystem II and photosystem I catalysed electron transfer. During this reaction, hydrogen peroxide is generated within the zooxanthellae cell and accordingly diffuses from the zooxanthellae cell into the coral's cytoplasm. Once inside the coral cytosol, the hydrogen peroxide may either be neutralised by enzymatic and non-enzymatic antioxidant pathways or be converted into a more noxious ROS, referred to as the hydroxyl radical.

According to Gregoire et al. ${ }^{20}$, chloroplast thylakoid membranes of Symbiodinium are exceptionally sensitive to thermal stress and can be irreversibly damaged. Bound to the thylakoid membrane are chlorophyll molecules which when damaged can result in the degradation of the entire photosynthetic apparatus and the loss of important photosynthetic products. Hill et al. ${ }^{21}$ suggested that the PSIl is the primary site of impact during coral bleaching and that the integrity and thermostability of the thylakoid membrane within the chloroplast of Symbiodinium is the major thermal-tolerant difference between species. The coral host may also influence the integrity and plasticity of the thylakoid membrane of Symbiodinium and therefore influence thermal acclimation and increase thermal tolerance of Symbiodinium. ${ }^{20,22}$

Thermal acclimation (a change in the lipid and protein composition) of the zooxanthellae thylakoid membranes during thermal fluctuations, has been demonstrated in species which inhabit warmer tropical regions and exhibit greater photosynthetic tolerance to elevated SST. ${ }^{22}$ This is a strong indication that the zooxanthellae play a vital role in the survival of the coral host by exhibiting thermal tolerance independent of that of the coral host. ${ }^{21}$ 


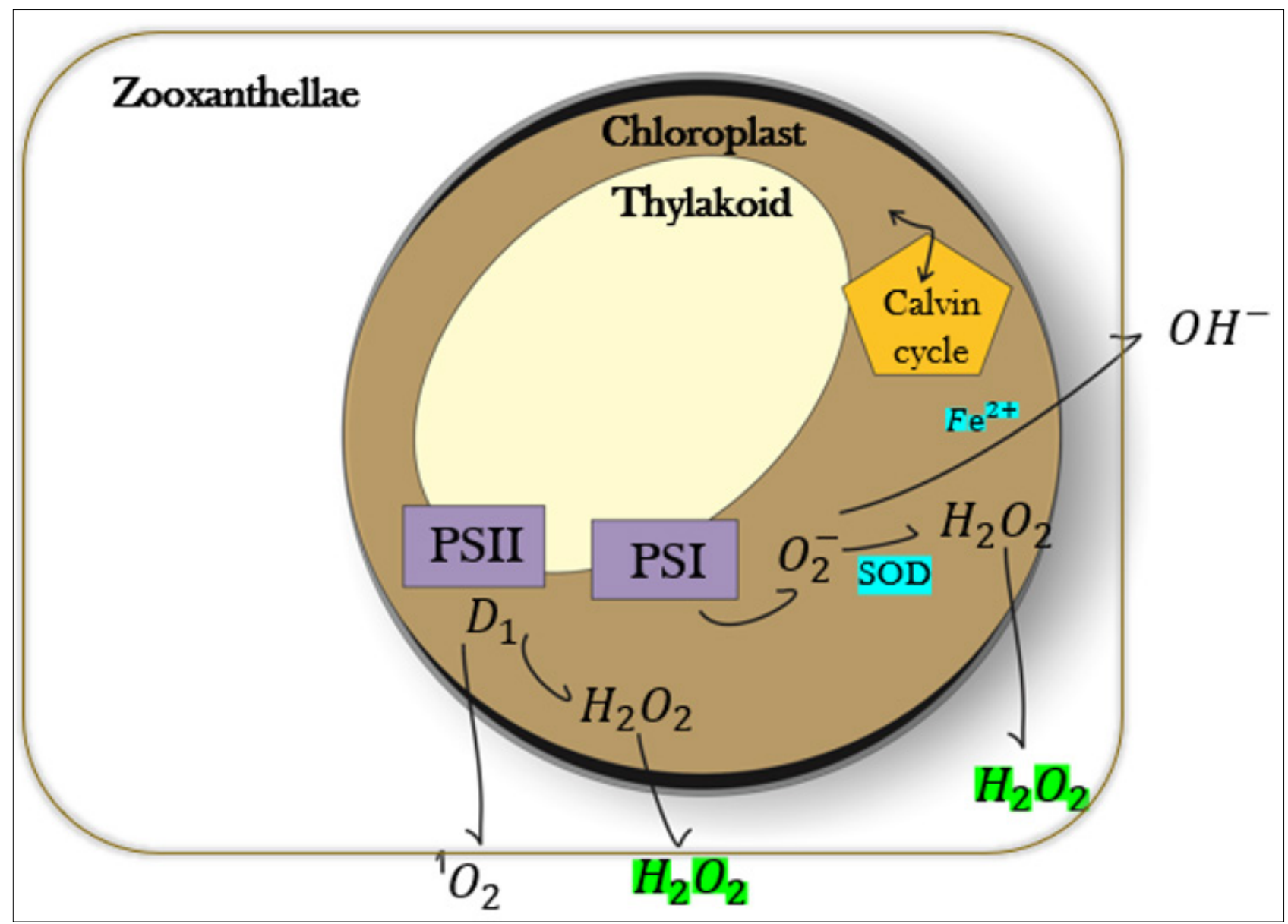

Figure 2: Schematic representation of the oxidative theory of coral bleaching within both the coral host and zooxanthellae endosymbiont, as described by Downs et al..$^{9}$ and Weis ${ }^{25}$.

\section{Function, activity, and effect of Hsps /chaperone proteins}

According to Rosic and co-workers ${ }^{8}$, Hsps are molecular chaperones that are responsible for protein folding and unfolding, aggregation, degradation and transport, thereby helping to regulate cellular reactions within a cell. Hsps are classified into families according to their molecular mass. Hsp70 and Hsp90 are two of the major cytosolic Hsps of Symbiodinium that contribute to the thermal stress response of the respective coral host. These Hsps are generally found in genotype C3 zooxanthellae.

Rosic et al..$^{8}$ conducted a study on these cytosolic Hsps and observed that $\mathrm{Hsp} 70$ can withstand temperature rises above $29^{\circ} \mathrm{C}$ (leading to an increased $H s p 70$ gene expression by up to $20 \%$ ), but temperatures above $35{ }^{\circ} \mathrm{C}$ decreased $\mathrm{Hsp} 70$ gene expression by $60 \%$. In contrast, elevated temperatures caused a decrease in $H s p 90$ gene expression. This may indicate that a reduction in the expression of Hsp90 inhibits a heat shock transcription factor (that regulates the expression of the heat shock proteins) and leads to the activation of heat-inducible genes and heat acclimation. This allows both the zooxanthellae and the coral to adapt to unforeseen temperature fluctuations. Symbiotic status did not control the expression of both Hsps genes; therefore, the initial thermal stress response is within the Symbiodinium, independent of the coral host.

Hsp90 operates as a dimer influencing development and epigenetic changes. According to Rosic et al. ${ }^{8}$, Hsp90 is represented in four forms: two cytosolic forms - an inducible alpha form as well as a constitutive beta form - and mitochondrial and endoplasmatic reticulum homologues. Induced Hsps are also present depending on the Symbiodinium genotype.
As a result, Hsps can exhibit genetic variation among individuals of a species and therefore a difference in stress tolerance.

Feder and Hofmann ${ }^{23}$ elaborated on the functions of different Hsps in zooxanthellae, and these are summarised in Table 2. Hsps mostly (1) interact with surrounding proteins and change their functions according to the cell's stress response, (2) recognise and bind to nonnative proteins and (3) function as oligomers. Cytoplasmic Hsp70 and mitochondrial Hsp70 are responsible for maintaining peptides in an unfolded conformation, which allows these peptides to be transported through pores situated in the mitochondrial membrane. Hsp60 and Hsp10 then assist in the folding of unfolded imported proteins within the mitochondria. ${ }^{23}$ Zooxanthellae are also able to modify and determine the amount of Hsps required for cell regulation and symbiosis.

According to Black et al. ${ }^{24}$, the physiological and distributional differences between the clades can influence which Hsps the zooxanthellae contain and to what extent they will be expressed (thermal tolerance or sensitivity). This suggests that due to zooxanthellae's ability to determine the amount and type of Hsps present during a heat response, the zooxanthellae can regulate both the host's respective Hsps as well as their own.

\section{Antioxidant response}

The antioxidant and cellular stress capacities of both the zooxanthellae and the coral host also influence the rate of coral bleaching, especially on more threatened coral reefs exposed to oxidative stress due to environmental variability such as elevated SSTs, increased light intensity and mechanical damage. Oxidative stress can be defined as the imbalance in the pro-oxidant/antioxidant ratio favouring pro-oxidant and leading to oxidative damage/stress. ${ }^{9}$ During mass coral bleaching, an increased amount of ROS is produced by the symbiont which concurrently results 
in oxidative stress in both the coral host and the symbiont. ROS are produced in the symbiont's chloroplast, which is associated with electron transfers between PSI and PSII, producing hydrogen peroxide. Antioxidant response mechanisms are in place to counteract increased levels of ROS, but, unfortunately, algal-generated hydrogen peroxide can diffuse from the algal symbiont into the coral cytoplasm, which, once inside, can either be neutralised by enzymatic and non-enzymatic antioxidant pathways or be converted into a more noxious ROS. ${ }^{9,25}$ This results in oxidative damage within the coral host and the coral host responds to the damage by expelling its symbiotic algal companion..$^{9,11}$

Table 2: Heat shock proteins and their functions necessary for cellular regulation during thermal stress of the coral host (adjusted from Hill et al. ${ }^{21}$ )

\begin{tabular}{|c|c|}
\hline Heat shock protein & Function \\
\hline Hsp10 & Protein folding in co-expression with Hsp60 \\
\hline Hsp27 & $\begin{array}{l}\text { Resistance to hydrogen peroxide, resistance to UV } \\
\text { radiation, tolerance to hyperthermia, accelerated } \\
\text { nuclear protein aggregation }\end{array}$ \\
\hline Crystallin & Cellular tolerance to hyperthermia \\
\hline Hsp60 & Tolerance to hyperthermia \\
\hline Hsp70 & $\begin{array}{l}\text { Cellular: tolerance to hyperthermia, recovery after } \\
\text { translational and transcriptional inhibition after heat } \\
\text { shock, regulation of heat-shock response, reduced } \\
\text { protein denaturation upon elevated heat exposure, } \\
\text { resistance to } \mathrm{H}_{2} \mathrm{O}_{2} \text {, tolerance of UV radiation, } \\
\text { apoptosis, resistance to apoptosis } \\
\text { Tissue/organ: reduction of hyperthermic damage } \\
\text { Organismal: tolerance to hyperthermia, regulation } \\
\text { of heat-shock response }\end{array}$ \\
\hline Hsp72 & $\begin{array}{l}\text { Apoptosis, protection against heat-induced nuclear } \\
\text { protein aggregation and thermal radio-sensitisation }\end{array}$ \\
\hline Hsp90 & Tolerance to hyperthermia, apoptosis \\
\hline Hsp101 & Tolerance to hyperthermia \\
\hline Many Hsps & $\begin{array}{l}\text { Recovery of cell proliferation and chromosome } \\
\text { damage after heat shock, tolerance to } \\
\text { hyperthermia }\end{array}$ \\
\hline HSF (Heat shock factor) & Thermo-tolerance \\
\hline
\end{tabular}

Downs et al. ${ }^{9}$ further states that antioxidant pathways such as the AsadaHalliwell pathway and xanthophyll cycling can be used to protect the coral host from oxidative damage by ROS. An individual can respond differently to each oxidative threat, depending primarily on higher or lower levels of antioxidant components within the individual species. Furthermore, specific Hsps can also protect both the coral host and its symbiont from oxidative stress through protecting glycolytic and electron-transport enzymes during photosynthesis and respiration. According to Downs et al. ${ }^{9}$, heat stress can further increase the possibility of hydrogen peroxide mediated oxidative stress by deactivating numerous hydrogen peroxide neutralising pathways.

According to Higuchi et al. ${ }^{10}$, antioxidant enzymes such as SOD, ascorbate peroxidase and CAT are responsible for detoxifying ROS. As a result, $\mathrm{SOD}$, ascorbate peroxidase and CAT act together to inactivate superoxide radicals and hydrogen peroxide and prevent coral hosts from bleaching. ${ }^{11}$ SOD is responsible for the dismutation of superoxide into oxygen and hydrogen peroxide, and CAT for the inactivation of hydrogen peroxide into water and oxygen. ${ }^{10}$ It is important to mention that an increase in hydrogen peroxide not only induces antioxidant activity within the exposed coral tissue, but these antioxidant activities also occur within the zooxanthellae tissue in response to an increase in ROS. ${ }^{11}$

\section{Genetic modification of Symbiodinium to enhance stress tolerance}

Several studies have suggested that environmental bioengineering can be an important consideration for future coral reef restoration strategies. ${ }^{12,13}$ The up-regulation of gene expression, which may mitigate thermal stress induction of any of the physiological aspects discussed earlier, can ensure stable coral-zooxanthellae symbiosis in the future. It presents a viable alternative strategy to preserve reefs amidst climate change.

However, even though zooxanthellae present promising candidates for genetic engineering, these dinoflagellates possess unusual biological features that have made gene editing within its genome difficult. ${ }^{12}$ They contain one of the largest nuclear genomes (1.5-112 Gbp) known, which exceeds that of the human haploid genome size. It is permanently condensed in liquid-crystalline chromosomes. Furthermore, transsplicing of polycistronic mRNAs occurs and plastid genomes are divided up into mini-circles. So far, the successful transformation of Symbiodinium has been validated in only two cases. ${ }^{26,27}$ In their study, Levin and co-workers ${ }^{12}$ propose a tailored genetic engineering framework for zooxanthellae that might overcome these obstacles and prevent stress-induced reactions that lead to bleaching, such as by using the CRISPR/Cas9 system.

\section{Is bleaching a threat to South African coral reefs?}

According to Celliers and Schleyer ${ }^{3}$, the South African coral reefs are located in a subtropical region and are the most southern coral reefs in the western Indian Ocean, and lack any topographical features, such as gullies and pinnacles, mainly due to less wave action and wave conformation within the increased depth. Sodwana Bay as well as all other South African reefs, form part of the high-latitude, sandstone reef structure and can be referred to as marginal reefs which are often falsely regarded as small and insignificant to the ecosystem when compared to massive reefs such as those on the Australian coast. ${ }^{28}$ However, South African reefs associated with the continental margins have survived severe coral bleaching events in the past millennium that went unnoticed.

South African and African reefs have been surprisingly less impacted from coral bleaching events than other tropical reefs such as the Great Barrier Reef, off the Australian coast, for two obvious reasons. Firstly, bleaching levels are highest at the shallowest sites, due to increased light penetration and solar irradiance as well as localised heating and ultraviolet radiation. As the minimum depth of South African coral reefs is about 8 metres, bleaching conditions are less severe than for coral reefs closer to the surface. As a result, a negative correlation is observed between depth and bleaching percentage. ${ }^{29}$

Secondly, seasonal upwelling also contributes to a lessening in South African coral bleaching. The upwelling developing from the Benguela Current on the west coast of South Africa is responsible for the uplifting of cooler waters during the El Niño event in 1998 and reduced coral bleaching ${ }^{30}$ As a result, seasonal upwelling protects the coral reefs from severe bleaching by breaking the intense heat stratification within the water column and reducing the heat irradiance upon the coral reefs. ${ }^{31}$

Africa's southernmost coral reef assemblages occur in the South African Maputaland reef complexes. The region is generally predicted to become wetter and warmer, and the water more acidic as a result of climate change. ${ }^{32}$ Temperature has been increasing regionally during the last century and a half. Because bleaching events have already become more frequent on the reefs of southern Africa, it is necessary to investigate how environmental stress leads to bleaching on these reefs. ${ }^{33}$

Within temperature anomalies and bleaching events such as the El Nino in 1998 , the SST $(<10 \mathrm{~m})$ increased by $3-5^{\circ} \mathrm{C}$, resulting in mortality of between $50 \%$ and $90 \%$ of coral in the central and western Indian 0cean. ${ }^{34}$ Luckily, the occurrence of seasonal upwelling along South Africa's continental shelf and bank moderated these increases in SST, preventing the subsequent coral bleaching within the surrounding area. ${ }^{28,29}$ Notably, depth has also played a considerable role in protecting South Africa's 
most iconic and unique reefs from devastation..$^{29}$ However, these factors may make South African reefs susceptible to bleaching due to small changes in SST that might go unnoticed by the rest of the world.

Even with the advantage of depth, wave energy and seasonal upwelling, community concern should be raised, and early response and preventative measures should already be in place for possible future bleaching anomalies. Coral communities that have shown increased mortality generally grow within shallow areas with restricted water circulation and may after prolonged exposure or continuous bleaching events become more tolerant to thermal stress and increase acclimation towards increased SST in comparison with coral communities situated at increased depths. ${ }^{29} \mathrm{As}$ a result, with recurring and continuous climate change, bleaching events, and subsequent heating of sea temperature downward into the water column, deeper distributed coral reefs may be at risk of high mortality, further resulting in ecosystem dysfunction. ${ }^{4}$ Upwelling events have also indicated lowered thermal thresholds amongst coral hosts and zooxanthellae, due to increased susceptibility of coral species to bleaching events which may occur within the future, uncontrolled and moderated by these upwellings. ${ }^{33}$

Coral mortality further creates opportunities for coral competitors such as algae and zoanthids to occupy the space made available by coral death and degradation. Fish communities shift from equally distributed and abundant herbivorous and corallivorous species to an increasing abundance of herbivorous fish communities which has further repercussions lower down and higher up in the trophic level. ${ }^{35}$ Finally, beaches which are regulated by reefs that reduce water action will be increasingly eroded. All these effects which occur from the loss of functioning reef ecosystems have an enormous impact on the community's socio-economic status and recoveries, such as tourism, local and provincial fisheries, and prevention of storms ${ }^{36}$ Numerous other recovery and monitoring strategies that could be implemented to decrease effects before and after bleaching events have been reported and elaborated on. ${ }^{36,37}$

Even with monitoring and recovery strategies available, little attention has been paid to assess future bleaching occurrences, the role coral symbiosis with the harboured zooxanthellae plays during coral bleaching, and how these endosymbionts may play a role in preventing future bleaching events. Another pressing concern is the limited amount of research on how environmental stress induces bleaching on South Africa's high-latitude reefs and their potential resistance, adaptations, acclimations, and community diversity and change, from the perspectives of both coral species and zooxanthellae.

The world's carbon footprint is increasing annually, and it can be viewed by recent research monitoring temperature fluctuations and increases on the 2 Mile reef in Sodwana Bay during the years 2007, 2008, 2011, 2012 and 2013. Resistance against coral bleaching of coral communities decreased, therefore resulting in coral bleaching across the entire slope. ${ }^{38}$ Increased percentage bleaching of $37.4 \%, 17.4 \%, 23.8 \%$, $33.6 \%$ and $38.8 \%$, respectively, per these annual readings indicate decreased thermal thresholds and possible acclimation. ${ }^{38}$ As a result, even if South Africa has deeper coral reefs, less wave destruction and less production of carbon products, future bleaching anomalies might be of too much risk to ignore in the present.

Sebastian et al. ${ }^{33}$ investigated the bleaching response of corals as well as their Symbiodinium community in southern Mozambique and observed that the most dominant scleractinian coral species were Stylophora pistillata, Montipora, Acropora, Pocillopora spp., Porites, Favites and Favia. During their study, Stylophora pistillata and Montipora were the most susceptible to elevated temperatures. The Symbiodinium harboured by the scleractinian corals belonged mostly to clade $\mathrm{C}$, of which two atypical C subclades were present in Stylophora pistillata and Pocillopora, which were more abundant in shallower sites. Clade D symbionts were also present but in lower amounts. Pocillopora harboured the most clade $D$ symbionts in comparison to the other coral species. Neither Symbiodinium clade A nor B were detected in any of the abovementioned coral colonies. Because clade $\mathrm{C}$ is the more thermally sensitive symbiont, South African corals are therefore vulnerable to elevated SSTs, should they occur in the future.

\section{Future research perspectives}

Future research perspectives include extending research on the use of CRISPR/Cas9-based genome editing of zooxanthellae, fuelling the genetic modification within the zooxanthellae's complex genomes. ${ }^{39}$ Gene drives can further be established to create reproducible inheritance systems of edited genetic material, thereby enhancing passage of a selected genotype to the offspring, both through sexual and asexual reproduction pathways, to spread the desired altered gene throughout the coral population..$^{39}$ Such studies and genomic procedures may also be considered to enhance the genomic stress responses of the coral itself. Physiological intervention may also be included in coral bleaching research needs, such as experimental research on pre-exposure to increase acclimation rate, adaptation opportunities, epigenetic modifications, and symbiont shuffling to enhance the stress tolerance of the coral host ${ }^{35}$ Genetic bioengineering and reproductive interventions, therefore, provide a plausible solution to increase genetic diversity within populations, increase acclimation and adaptation rates to a changing environment and permit the selection of traits that may improve coral resilience, persistence, and restoration strategies within future climate change..$^{35}$

\section{Conclusion}

Coral reefs are vital to marine ecosystems and nutrient cycles but are unfortunately being increasingly damaged, mainly as a result of global warming. Elevated SST has led to coral bleaching, which is the disablement of the coral-algae symbiosis primarily due to photosynthetic dysfunction. There are, however, numerous protective measures to ensure that the coral tissue and the photosynthetic apparatus of the zooxanthellae are preserved and kept in a stable physiological condition during elevated temperatures. One of these measures is through Hsps, which play a vital role in the refolding of heat-stressed unfolded proteins, protecting stress-damaged proteins, transporting of transcribed proteins and inserting those proteins into organelles within both the zooxanthellae and the coral host. Antioxidant enzymes released by both symbionts and coral hosts also prevent coral bleaching through mitigating oxidative stress. Heterogeneous zooxanthellae genotypes can influence bleaching susceptibility towards thermal resilience upon temperature fluctuations due to their physiological and genetic diversity. As a result, coral bleaching is dependent on the Hsps expressed and the heterogeneous zooxanthellae genotypes present within the holobiont. South African reefs may have the ability to act as a refugee area for damaged coral reefs, but should still be actively monitored and researched to better predict future coral beaching occurrences and the effects they may have on the entire marine ecosystem. Genetic bioengineering within zooxanthellae endosymbionts has been suggested to be the turning point in coral bleaching, but numerous strategies are still to be explored in which this could be done successfully.

\section{Competing interests}

We have no competing interests to declare.

\section{Authors' contributions}

A.C. is a postgraduate student and was responsible for the literature review, writing the initial draft, and writing revisions. S.B. is the study leader and was responsible for the conceptualisation, funding acquisition and project management; and contributed to the writing of the manuscript.

\section{References}

1. Souter DW, Linden 0 . The health and future of coral reef systems. Ocean Coast Manag. 2000;43(8-9):657-688. https://doi.org/10.1016/S09645691(00)00053-3

2. Hughes TP, Anderson KD, Connolly SR, Heron SF, Kerry JT, Lough JM, et al. Spatial and temporal patterns of mass bleaching of corals in the Anthropocene. Science. 2018;359(6371):80-83. https://doi.org/10.1126/science.aan8048 
3. Celliers L, Schleyer MH. Coral community structure and risk assessment of high-latitude reefs at Sodwana Bay, South Africa. Biodivers Conserv. 2008;17:3097-3117. https://doi.org/10.1007/s10531-007-9271-6

4. Mcclanahan T, Ateweberhan M, Sebastian C, Graham N, Wilson S, Guillaume $M$, et al. Western Indian Ocean coral communities: Bleaching responses and susceptibility to extinction. Mar Ecol Prog Ser. 2007;337:1-13. https://doi. org/10.3354/meps337001

5. Piggot AM, Fouke BW, Sivaguru M, Sanford RA, Gaskins HR. Change in zooxanthellae and mucocyte tissue density as an adaptive response to environmental stress by the coral, Montastraea annularis. Mar Biol. 2009;156(11):2379-2389. https://doi.org/10.1007/s00227-009-1267-1

6. LaJeunesse TC, Parkinson JE, Gabrielson PW, Jeong HJ, Reimer JD, Voolstra $\mathrm{CR}$, et al. Systematic revision of Symbiodiniaceae highlights the antiquity and diversity of coral endosymbionts. Curr Biol. 2018;28(16):2570-2580.e6. https://doi.org/10.1016/j.cub.2018.07.008

7. Takahashi S, Nakamura T, Sakamizu M, Van Woesik R, Yamasaki H. Repair machinery of symbiotic photosynthesis as the primary target of heat stress for reef-building corals. Plant Cell Physiol. 2004;45(2):251-255. https://doi. org/10.1093/pcp/pch028

8. Rosic NN, Pernice M, Dove S, Dunn S, Hoegh-Guldberg 0. Gene expression profiles of cytosolic heat shock proteins Hsp70 and Hsp90 from symbiotic dinoflagellates in response to thermal stress: Possible implications for coral bleaching. Cell Stress Chaperones. 2011;16(1):69-80. https://doi. org/10.1007/s12192-010-0222-x

9. Downs CA, Fauth JE, Halas JC, Dustan P, Bemiss J, Woodley CM. Oxidative stress and seasonal coral bleaching. Free Radic Biol Med. 2002;33(4):533543. https://doi.org/10.1016/s0891-5849(02)00907-3

10. Higuchi T, Fujimur, H, Arakaki T, Oomori T. Activities of antioxidant enzymes (SOD and CAT) in the coral Galaxea fascicularis against increased hydrogen peroxide concentrations in seawater. In: Riegl B, Dodge RE, editors. Proceedings of the 11th International Coral Reef Symposium; 2008 July 7-11; Ft. Lauderdale, FL, USA. Hollywood, FL: HCNSO, NSU; 2008. p. 926-930.

11. Lesser MP. Oxidative stress causes coral bleaching during exposure to elevated temperatures. Coral Reefs. 1997;16(3):187-192. https://doi. org/10.1007/s003380050073

12. Levin RA, Voolstra CR, Agrawal S, Steinberg PD, Suggett DJ, Van Oppen $\mathrm{MJH}$. Engineering strategies to decode and enhance the genomes of coral symbionts. Front Microbiol. 2017;8:1220. https://doi.org/10.3389/ fmicb.2017.01220

13. Piaggio AJ, Segelbacher G, Seddon PJ, Alphey L, Bennett EL, Carlson RH, et al. Is it time for synthetic biodiversity conservation? Trends Ecol Evol. 2017;32(2):97-107. https://doi.org/10.1016/j.tree.2016.10.016

14. Gilbert SF, McDonald E, Boyle N, Buttino N, Gyi L, Mai M, et al. Symbiosis as a source of selectable epigenetic variation: Taking the heat for the big guy. Philos Trans R Soc Lond B Biol Sci. 2010;365(1540):671-678. https://doi. org/10.1098/rstb.2009.0245

15. Jones A, Berkelmans R. Potential costs of acclimatization to a warmer climate: Growth of a reef coral with heat tolerant vs. sensitive symbiont types. PLoS ONE. 2010;3(5), e10437. https://doi.org/10.1371/journal.pone.0010437

16. Carilli J, Donner SD, Hartmann AC. Historical temperature variability affects coral response to heat stress. PLoS ONEe. 2012;7(3), e34418. https://doi. org/10.1371/journal.pone.0034418

17. Levin RA, Beltran VH, Hill R, Kjelleberg S, McDougald D, Steinberg PD, et al. Sex, scaverngers, and chaperones: Transcriptome secrets of divergent Symbiodinium thermal tolerances. Mol Biol Evol. 2016;33(9):2201-2215. https://doi.org/10.1093/molbev/msw119

18. Chauka LJ, Steinert G, Mtolera MSP. Influence of local environmental conditions and bleaching histories on the diversity and distribution of Symbiodinium in reef-building corals in Tanzania. Afr J Mar Sci. 2016;38(1):57-64. https://doi. org/10.2989/1814232X.2015.1123771

19. Smith D, Suggett D, Baker N. Is photoinhibition of zooxanthellae photosynthesis the primary cause of thermal bleaching in corals? Global Change Biol. 2005;11:1-11. https://doi.org/10.1111/j.1529-8817.2003.00895.x
20. Grégoire V, Schmacka F, Coffroth MA, Karsten U. Photophysiological and thermal tolerance of various genotypes of the coral endosymbiont Symbiodinium sp. (Dinophyceae). J Appl Phycol. 2017;29:1893-1905. https://doi.org/10.1007/s10811-017-1127-1

21. Hill R, Ulstrup KE, Ralph PJ. Temperature induced changes in thylakoid membrane thermostability of cultured, freshly isolated, and expelled zooxanthellae from scleractinian corals. Bull Mar Sci. 2009;85(3):223-244.

22. Berkelmans R, Van Oppen MJH. The role of zooxanthellae in the thermal tolerance of corals: A 'nugget of hope' for coral reefs in an era of climate change. Proc R Soc B Biol Sci. 2006;273(1599):2305-2312. https://doi. org/10.1098/rspb.2006.3567

23. Feder ME, Hofmann GE. Heat-shock proteins, molecular chaperones, and the stress response: Evolutionary and ecological physiology. Annu Rev Physiol. 1999;61:243-282. https://doi.org/10.1146/annurev.physiol.61.1.243

24. Black NA, Voellmy R, Szmant AM. Heat shock protein induction in Montastraea faveolata and Aiptasia pallida exposed to elevated temperatures. Biol Bull. 1995;188(3):234-240. https://doi.org/10.2307/1542301

25. Weis VM. Cellular mechanisms of cnidarian bleaching: Stress causes the collapse of symbiosis. J Exp Biol. 2008;211(19):3059-3066. https://doi. org/10.1242/jeb.009597

26. Ten Lohuis MR, Miller DJ. Genetic transformation of dinoflagellates (Amphidinium and Symbiodinium): Expression of GUS in microalgae using heterologous promoter constructs. Plant J. 1998;13(3):427-435. https://doi. org/10.1046/j.1365-313X.1998.00040.x

27. Ortiz-Maramoros MF, Villanueva MA, Islas-Flores T. Transient transformation of cultured photosynthetic dinoflagellates (Symbiodinium spp.) with planttargeted vectors. Ciencias Marinas. 2015; 41(1):21-32. https://doi. org/10.7773/cm.v41i1.2449

28. Schleyer MH, Celliers L. Biodiversity on the marginal coral reefs of South Africa: What does the future hold? Zool Verh Leiden. 2003;345:387-400.

29. Floros CD, Samways MJ, Armstrong B. Taxonomic patterns of bleaching within a South African coral assemblage. Biodivers Conserv. 2004;13(6):11751194. https://doi.org/10.1023/B:BIOC.0000018151.67412.c7

30. Riegl B. Climate change and coral reefs: Different effects in two high-latitude areas (Arabian Gulf, South Africa). Coral Reefs. 2003;22:433-446. https:// doi.org/10.1007/s00338-003-0335-0

31. Goschen WS, Schumann EH. Upwelling and the occurrence of cold water around Cape Recife, Algoa Bay, South Africa. S Afr J Mar Sci. 1995;16(1):5767. https://doi.org/10.2989/025776195784156520

32. South African Department of Environmental Affairs (DEA). Long-term adaptation scenarios flagship research programme (LTAS) for South Africa. Climate trends and scenarios for South Africa. Pretoria: DEA; 2013.

33. Sebastián R, Sink KJ, McClanahan TR, Cowan DA. Bleaching response of corals and their Symbiodinium communities in southern Africa. Mar Biol. 2009;156(10):2049-2062. https://doi.org/10.1007/s00227-009-1236-8

34. Souter D, Obura D, Lindén 0 . Coral reef degradation in the Indian Ocean. Status report. Kalmar: CORDIO; 2000

35. US National Academies of Sciences, Engineering, and Medicine. A research review of interventions to increase the persistence and resilience of coral reefs. Washington DC: The National Academies Press; 2019. https://doi. org/10.17226/25279

36. Obura D, Gudka M, Abdou Rabi F, Bacha Gian S, Bijoux J, Freed S, et.al. Coral reef status report for the Western Indian Ocean. Global Coral Reef Monitoring Network (GCRMN) / International Coral Reef Initiative (ICRI); 2017. p. $122-$ 131

37. Schleyer MH, Celliers L. The status of South African coral reefs. In: Souter D Obura D, Lindén 0, editors. Coral reef degradation in the Indian 0cean. Status report. Kalmar: CORDIO; 2000

38. Harikishun A. Coral bleaching responses in Sodwana Bay, South Africa [thesis]. Cape Town: University of Cape Town; 2013.

39. Spicer A, Molnar A. Gene editing of microalgae: Scientific progress and regulatory challenges in Europe. Biology. 2018:7(21):1-13. https://doi org/10.3390/biology 7010021 